\title{
A comparison of the bacteria found on the hands of 'homemakers' and neonatal intensive care unit
} nurses

\author{
A.E. Aiello ${ }^{a}$, J. Cimiotti ${ }^{\text {b }}$ P. Della-Latta ${ }^{\text {, }}$ E.L. Larson ${ }^{\text {,** }}$ \\ ${ }^{a}$ The Joseph L. Mailman School of Public Health, Columbia University, New York, NY, USA \\ ${ }^{\mathrm{b}}$ Columbia University School of Nursing, New York, NY, USA \\ ${ }^{c}$ Columbia Presbyterian Medical Center, New York, NY, USA
}

Received 27 February 2003; accepted 27 March 2003

\section{KEYWORDS}

Antibiotic resistance hospital; Community hand hygiene

\section{Introduction}

Gram-negative bacteria (GNB), coagulase-negative

${ }^{*}$ Corresponding author. Tel.: +1-212-305-0723; fax: +1-212305-0722.

E-mail address: ell23@columbia.edu

\begin{abstract}
Summary This prevalence study was conducted to compare the counts, types and antimicrobial resistance profiles of bacterial flora on the hands of individuals in the community to that of nurses at a nearby university teaching hospital, with an intense hand hygiene regimen. Hand cultures were obtained from 204 individuals during a home visit and 119 nurses in two neonatal intensive care units (NICUs). The mean total log counts of organisms were 5.73 and 5.24 for the homemakers [defined as the person (usually the mother) who is the primary person responsible for arranging childcare, cooking, cleaning etc] and nurse hands, respectively $(P<0.0001)$. Significantly more homemakers had Acinetobacter Iwoffii, Enterobacter cloacae, Klebsiella pneumoniae, Pseudomonas aeruginosa, P. fluorescens/putida, and Staphylococcus aureus on their hands compared with the nurses (all $P<0.05$ ). However, significantly more nurses had Enterococcus faecalis, S. epidermidis, and S. warneri on their hands $(P<0.05)$. Of note, the hands of nurses harboured significantly more $S$. epidermidis strains resistant to amoxicillin/clavulanate, cefazolin, clindamycin, erythromycin, and oxacillin and S. warneri resistant to amoxicillin/clavulanate, cefazolin, clindamycin, and oxacillin $(P<0.05)$. Surprisingly, significantly more trimethoprim/sulfamethoxazole-resistant S. epidermidis and ciprofloxacin-resistant $S$. warneri was recovered from the hands of homemakers $(P<0.05)$. This study demonstrates differences in prevalence, bacterial composition and antimicrobial resistance of hand flora of hospital personnel compared with homemakers. Moreover, the hands of homemakers may serve as community reservoirs for antimicrobial resistant strains of clinical importance.

(c) 2003 The Hospital Infection Society. Published by Elsevier Science Ltd. All rights reserved.
\end{abstract}


personnel and patients versus healthy individuals. ${ }^{13-20}$ A higher prevalence of antibiotic-resistant organisms on the hands of patient-care staff versus non-patient-care staff and/or outpatients has been reported. ${ }^{13,15,19-22}$

While most of these studies have compared the bacterial flora of populations within the hospital environment, only a few have examined whether hospital staff versus individuals within the community carry similar amounts and types of GNB, CNS, or S. aureus on their hands and whether the antibioticresistance patterns for these organisms are similar. ${ }^{16-18,20}$ Although data addressing these issues were published more than two decades ago, hand hygiene regimens within the hospital have since changed dramatically, ${ }^{12}$ therefore, the purpose of this study was to compare the quantities, types and antibiotic resistance profiles of bacteria recovered from the hands of homemakers [defined as the person (usually the mother) who is the primary person responsible for arranging childcare, cooking, cleaning etc] and neonatal intensive care unit (NICU) nurses. As lower levels of hand hygiene are practiced within the community setting, it was hypothesized that the hands of individuals at home would have higher overall bacterial counts, greater prevalence of GNB and fewer antibiotic-resistant organisms than nurses.

\section{Methods}

\section{Sample and setting}

The population sampled consisted of 204 homemakers within the Washington Heights community in northern Manhattan. This area is representative of inner city neighbourhoods, with a predominantly immigrant population of mixed poor, working poor, and middle class groups. It is densely populated with many households having several generations of families often with young children. Inclusion was limited to those living in units with three or more individuals, and at least one preschool child.

Three primary sources were used to identify and recruit potential participants for the home sample: local churches, preschools and elementary schools; three local Women, Infants and Children (WIC) offices; and neighbourhood referrals. Recruitment was by word-of-mouth, referral, and a flyer. A highly experienced and trained interviewer who lived in the community recruited participants.

The nurse sample consisted of 119 full-time staff nurses from two large, level III neonatal intensive care units (NICUs) in New York City, that are part of the New York Presbyterian Hospital System: a 50bed unit at the New York Weill Cornell Medical Centre and a 47-bed unit at the Children's Hospital of New York. Both units practised the same infection control policies and procedures.

\section{Hand cultures}

Institutional Review Board approval was obtained and participants provided written consent. A hand culture was obtained from each participant. Before sampling, participants cleansed their hands for $10 \mathrm{~s}$ using their assigned hand hygiene regimen. In the homemakers, this was either plain, liquid soap or a similarly formulated soap containing $0.2 \%$ triclosan. The nurses used either a liquid detergent containing $4 \%$ chlorhexidine gluconate or a hand rinse containing $60 \%$ ethyl alcohol. This short wash removed the majority of transient flora so that changes in the subjects' resident flora could be better determined. A modified glove-juice technique was used. The participant inserted the dominant hand into a sterile polyethylene bag containing $50 \mathrm{~mL}$ of sampling solution $(0.075 \mathrm{M}$ phosphate buffer, $\mathrm{pH} 7.9$, containing $0.1 \%$ polysorbate 80 , and $0.1 \%$ sodium thiosulphate). This solution neutralized any residual antiseptic and dispersed the macrocolonies into single cells for quantitation. The entire hand was massaged through the wall of the bag for $1 \mathrm{~min}$ and samples were taken to the microbiology laboratory within $4 \mathrm{~h}$ for processing. Samples were obtained by the trained interviewer in the home group, and a graduate research assistant in the nurse group. They were processed by a microbiology technologist specifically trained for this task.

\section{Microbiology procedures}

An inoculum of $0.1 \mathrm{~mL}$ of sampling solution (undiluted, 1:10 and 1:100 dilutions) was plated onto the following agar media: Columbia sheep blood agar (5\%), MacConkey, Columbia colistinnalidixic acid (CNA), Sabouraud's with chloramphenicol and gentamicin and bile aesulin agar (Becton Dickinson Microbiology Systems, Sparks, MD, USA). All plates were incubated at $35^{\circ} \mathrm{C}$ and observed daily for growth over $48 \mathrm{~h}$. Speciation of bacteria was performed using the MicroScan system (Dade Behring, Deerfield, IL, USA) and staphylococci further identified by coagulase and Staphaurex (Murex Biotech Limited, Norcross, GA, USA).

\section{Antibiotic resistance testing}

Methicillin and vancomycin resistance was determined for all staphylococol strains and vancomycin 
resistance for enterococci by inoculation on to oxacillin screen agar (Becton Dickinson, Sparks, MD, USA) and Columbia CNA with vancomycin (Remel, Lenexa, KS, USA), respectively.

All bacterial isolates were tested by the microtitre broth dilution method (MicroScan, Dade Behring, Deerfield, IL, USA) using a panel containing 14-21 antibiotics.

\section{Data analysis}

$t$-Tests, (SPSS, Chicago, IL, USA) were conducted to compare counts of bacteria between the homemakers using either soap product and between the nurses using the two hand hygiene products. There were no significant differences in counts between soap groups in either the nurses $(P \geq 0.513)$ or the homemakers $(P \geq 0.267)$. Therefore, for all other analyses, the two groups of nurses and the two of homemakers were combined. A $t$-test was conducted to compare counts of bacteria on the homemakers' versus the nurses' hands. Chi-square or Fisher's exact tests were used to compare the proportions of different types of organisms and the proportions of antibiotic-resistant bacteria isolated from homemakers' versus nurses' hands (STATA, College Station, TX, USA). For statistical purposes, only bacterial isolates that were found on the hands of four or more nurses and homemakers were included in the antibiotic resistance analysis. In addition, only organisms that were found on nine or more nurses or homemakers were included in the comparisons of the proportions of different types of organisms.

\section{Results}

There were no significant differences in sex between homemakers and nurses $(P>0.05)$ but nurses were significantly older (mean age: 42 versus 34 years, $P<0.0001$ ). The mean total $\log _{10}$ counts of organisms on the hands were 5.70 and 5.16 for the homemaker and nurse hands, respectively $(P<0.0001)$.

There were 48 and 12 different species of GNB, and 12 and 11 different species of CNS on the homemaker and nurse hand samples, respectively. There were four nurses and 32 homemakers with $S$. aureus on their hands. The five most prevalent species of bacteria found on the hands of the 204 homemakers were: Pseudomonas fluorescens/putida (59), Staphylococcus warneri (56), Klebseilla pneumoniae (44), S. aureus (32), and Enterobacter cloacae (26). The five most prevalent species of

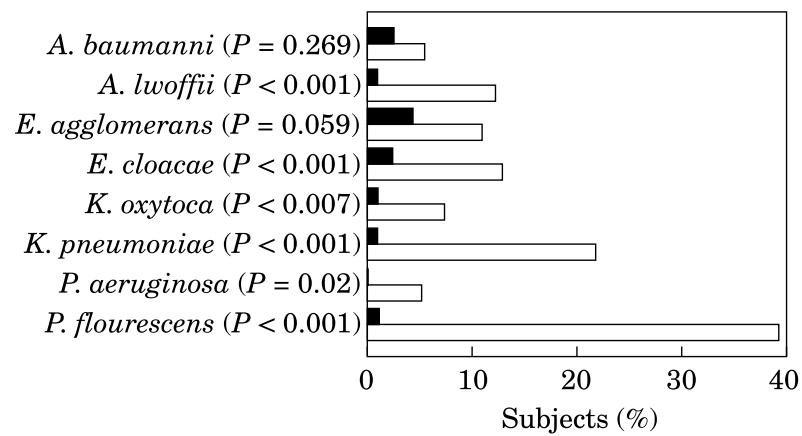

Figure 1 Prevalence of GNB on hands of homemakers and nurses. ( $\square)$ Homemakers $(N=204)$; (ם) Nurses $(N=119)$.

bacteria found on the hands of the 119 nurses were: S. epidermidis (77), S. warneri (75), Enterococcus faecalis (nine), S. hominis (six), and Enterobacter agglomerans (five). Significantly more homemakers had Acinetobacter lwoffii, E. cloacae, K. oxytoca, $K$. pneumoniae, Pseudomonas aeruginosa, $P$. fluorescens/putida, and $S$. aureus on their hands compared with the nurses (all $P<0.05$; Figures 1 and 2). However, significantly more nurses had $E$. faecalis, S. epidermidis, and S. warneri on their hands as compared with homemakers (all $P<0.05$ ). Lastly, there were no significant differences in the numbers of homemakers versus nurses with $A$. baumannii and E. agglomerans.

The percentages of antibiotic-resistant staphylococcal isolates found are depicted in Table I. There was a significantly greater proportion of amoxicillin/ clavulanate-, cefazolin-, clindamycin-, erythromycin-, and oxacillin-resistant S. epidermidis isolated from the hands of nurses versus homemakers. In addition, there was a significantly greater proportion of amoxicillin/clavulanate-, cefazolin-, clindamycin-, and oxacillin-resistant $S$. warneri isolated from the hands of nurses versus homemakers. However, there was a significantly greater proportion of trimetho$\mathrm{prim} / \mathrm{sulfamethoxazole-resistant} \mathrm{S.} \mathrm{epidermidis} \mathrm{and}$

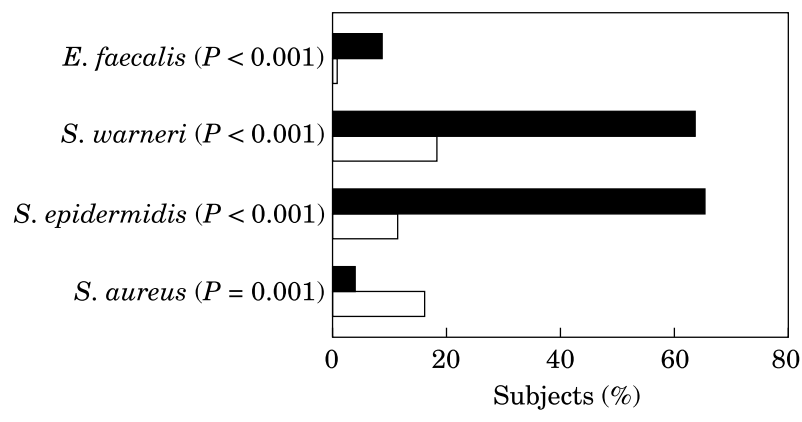

Figure 2 Prevalence of $E$. faecalis and staphylococci on hands of homemakers and nurses. ( $\square)$ Nurses $(N=119)$; $(\square)$ Homemakers $(N=204)$. 
Table I Percent of antibiotic-resistant isolates among nurses and homemakers

\begin{tabular}{|c|c|c|c|c|c|c|c|c|c|c|c|}
\hline \multirow[b]{2}{*}{ Study Pop. } & \multirow[b]{2}{*}{ Organisms $(N)$} & \multicolumn{10}{|c|}{ Percent of antibiotic-resistant isolates } \\
\hline & & $\mathrm{AM} / \mathrm{CLA}$ & CFZ & CLN & CIP & ERY & LVX & OXA & TET & $\mathrm{T} / \mathrm{S}$ & VAN \\
\hline Nurse & S. aureus (4) & 0 & 25 & 25 & 0 & 25 & 0 & 0 & 0 & 0 & 0 \\
\hline Home & S. aureus (32) & 6 & 6 & 0 & 0 & 9 & 0 & 6 & 0 & 0 & 0 \\
\hline Nurse & S. capitis (7) & 0 & 0 & 29 & 0 & 57 & 14 & 0 & 0 & 0 & 0 \\
\hline Home & S. capitis (7) & 29 & 29 & 43 & 57 & 86 & 43 & 29 & 29 & 43 & 0 \\
\hline Nurse & S. epidermidis (77) & $88^{*}$ & $90^{*}$ & $68^{*}$ & 6 & $94^{*}$ & 9 & $90^{*}$ & 10 & $9^{*}$ & 0 \\
\hline Home & S. epidermidis (22) & $32^{*}$ & $32^{*}$ & $27^{*}$ & 14 & $77^{*}$ & 9 & $32^{*}$ & 18 & $32^{*}$ & 0 \\
\hline Nurse & S. warneri (75) & $85^{*}$ & $85^{*}$ & $65^{*}$ & $0^{*}$ & 89 & 17 & $85^{*}$ & 7 & 1 & 0 \\
\hline Home & S. warneri (56) & $39^{*}$ & $39^{*}$ & $13^{*}$ & $21^{*}$ & 80 & 7 & $39^{*}$ & 14 & 0 & 0 \\
\hline
\end{tabular}

$\mathrm{AM} / \mathrm{CLA}=$ amoxicillin/clavulanate, $\mathrm{CFZ}=$ cefazolin, $\mathrm{CLN}=$ clindamycin, $\mathrm{CIP}=$ ciprofloxacin, $\mathrm{ERY}=$ erythromycin, $\mathrm{LVX}=$ levofloxacin, $\mathrm{OXA}=$ oxacillin, $\mathrm{TET}=$ tetracycline, $\mathrm{T} / \mathrm{S}=$ trimethoprim/sulfamethoxazole. ${ }^{*}$ Significant differences $(P<0.05)$ by Chi' ${ }^{2}$ or Fisher's Exact Test.

ciprofloxacin-resistant S. warneri isolated from the hands of homemakers. Of the five E. agglomerans isolates from nurses' hands, none were resistant to the antibiotics tested (amikacin, aztreonam, ceftazidime, ciprofloxacin, cefepime, ceftriaxone, gentamicin, imipenem, levofloxacin, meropenem, piperacillin/ tazobactam, ticarcillin/clavulanate, tobramycin, and trimethoprim/sulfamethoxazole). Of the 22 isolates of $E$. agglomerans found on the homemaker's hands, five were resistant to ceftriaxone and nine were resistant to ticarcillin/clavulanate.

\section{Discussion}

\section{Types of flora}

These data suggest that the types and numbers of bacterial flora on the hands of nurses working in the NICUs, where an intense hand hygiene regimen is required, varies to that of individuals in the community setting. Other studies have compared the hand flora of healthcare personnel with that of non-patient-care staff or other control groups, but were made several decades ago. ${ }^{14,16-18,23}$ However the results are surprisingly consistent with our study. For example, a few studies have shown lower counts of bacteria on the hands of nurses versus on the hands of individuals with no hospital association. ${ }^{16,18}$ In the study by McBride et al., ${ }^{18}$ highest bacterial counts were found on hands of housewives. One study comparing hospital staff with community controls, with no association to the hospital environment, reported a higher proportion of control subjects carrying GNB. ${ }^{16}$ We found a similar pattern when comparing the most prevalent GNB, with the exception of Citrobacter spp. which had been prevalent only in 1981 .
In 1981, 22 different types of GNB were found on the hands, and the same distribution of species types was present in both nurses and controls. This supported the conclusion that the hospital handwashing regimen did not change the ecological balance of GNB. ${ }^{16}$ Conversely, in our study 48 different types of GNB were isolated from homemakers' hands and only 12 on nurses' hands. This may indicate an influence of the hand hygiene products and frequency of hygiene or hand hygiene techniques used exclusively by nurses. Indeed, neither of the products used by our nurses was available several decades ago. The differences in GNBs may also be attributed to variations in exposure to bacterial populations. For example, individuals within the home environment may be more likely to come in contact with transient GNB on fomites (e.g. during food preparation or cleaning) when compared with nurses in a hospital environment. A study by Guenther et al. ${ }^{23}$ reported that GNB were more frequently found on the hands of nurses when they had just arrived to work from home versus later on in their working shift.

There are few data comparing CNS on nurses' hands versus community controls. Similar to the findings of this study, McBride et al. ${ }^{17}$ found CNS more often on nurses' hands versus controls'. ${ }^{17}$ In another study, McBride et al. ${ }^{20}$ found the same proportion of nurses and controls with $S$. aureus on their hands. ${ }^{20} \mathrm{~A}$ more recent study comparing medical and non-medical personnel found a higher frequency of $S$. aureus on hands of non medical personnel versus medical personnel, which is consistent with our findings. ${ }^{14}$

\section{Antimicrobial resistance of flora}

For most antibiotics tested, nurses in this study, had 
a greater proportion of antibiotic-resistant staphylococci on their hands as compared with homemakers. Several studies have reported a similar trend comparing medical personnel and non-medical personnel and/or community controls. ${ }^{13-15,20,24}$ One study reported that methicillin-resistant CNS was significantly higher among nurses with closest and most frequent patient contact. ${ }^{13}$ A study by Cespedes et al. ${ }^{14}$ found that significantly more medical personnel compared with non-medical hospital personnel were colonized with antibiotic-resistant $S$. aureus.

Antimicrobial resistance in the skin flora of nurses seems to be associated with patient contact rather than with antibiotic consumption as observed in the community setting. Clearly, high levels of antibiotic-resistant isolates comprising the skin flora of care-givers is undesirable because this serves as a potential reservoir for antimicrobial resistance in the healthcare environment. The finding that high levels of antimicrobial-resistant skin flora among healthcare personnel persist despite heightened hand hygiene interventions in recent years suggests that these practices alone have been unsuccessful deterrents to the acquisition of resistant strains. This is disconcerting and underscores the importance of continued research to optimize infection control practices that might reduce the risk of skin colonization with antimicrobial-resistant bacteria.

Antibiotic resistance in the community is an emerging problem. ${ }^{25-27}$ In our study, there was a significantly greater proportion of trimethoprim/ sulfamethoxazole-resistant S. epidermidis and ciprofloxacin-resistant $S$. warneri from the hands of homemakers. These findings were unexpected. An earlier study among the same group of homes indicated probable over-use of antibiotics. ${ }^{28}$ Of the individuals within the homes reporting symptoms of infectious illness, over one-third took an antibiotic, whereas most of the reported symptoms were indicative of viral illness. ${ }^{28}$ Trimethoprim/sulfamethoxazole (TMP-SMX) is commonly prescribed for urinary tract infections (UTIs) ${ }^{29}$ and, resistance to TMP-SMX ranges from $18-22 \%$ in various parts of the US. ${ }^{30,31}$

We were unable to find data on ciprofloxacin resistance in S. warneri, although ciprofloxacinresistant Neisseria gonorrhoeae has been increasingly identified in the US. ${ }^{32}$ A study investigating trends in antibiotic-resistant Escherichia coli associated with UTI, reported that ciprofloxacinresistance increased from $0.7 \%$ in 1995 to $2.5 \%$ in $2001 .^{33}$ In addition, resistance to ciprofloxacin has been associated with Campylobacter spp. infections in individuals returning from Thailand. ${ }^{34}$ While
CNS species such as $S$. warneri are of little clinical interest because they are unlikely to be associated with nosocomial infections, they may be important as community reservoirs of antibiotic resistance.

It is evident that working in a healthcare setting influences bacterial flora of the hands-benefically (i.e. lower counts on the hands of the nurses) and detrimentally (i.e. higher proportions of antibiotic resistance on the hands of the nurses). The hands of homemakers may serve as community reservoirs for resistance to certain antibiotics of clinical importance. Further research concerning the prevalence of antibiotic resistance for a variety of bacterial species found on the hands of individuals in the community setting is needed.

\section{References}

1. Gould D. Nurses' hands as vectors of hospital-acquired infection: a review. J Adv Nurs 1991;16:1216-1225.

2. Richards MJ, Edwards JR, Culver DH, Gaynes RP. Nosocomial infections in coronary care units in the United States. National Nosocomial Infections Surveillance System. Am J Cardiol 1998;82:789-793.

3. Richards MJ, Edwards JR, Culver DH, Gaynes RP. Nosocomial infections in pediatric intensive care units in the United States. National Nosocomial Infections Surveillance System. Pediatrics 1999;103:e39.

4. Shah SS, Ehrenkranz RA, Gallagher PG. Increasing incidence of Gram-negative rod bacteraemia in a newborn intensive care unit. Pediatr Infect Dis J 1999;18:591-595.

5. Richards MJ, Edwards JR, Culver DH, Gaynes RP. Nosocomial infections in combined medical-surgical intensive care units in the United States. Infect Control Hosp Epidemiol 2000;21: 510-515.

6. Richards MJ, Edwards JR, Culver DH, Gaynes RP. Nosocomial infections in medical intensive care units in the United States. National Nosocomial Infections Surveillance System. Crit Care Med 1999;27:887-892.

7. Nambiar S, Singh N. Change in epidemiology of health careassociated infections in a neonatal intensive care unit. Pediatr Infect Dis J 2002;21:839-842.

8. Sanderson PJ, Weissler S. Recovery of coliforms from the hands of nurses and patients: activities leading to contamination. J Hosp Infect 1992;21:85-93.

9. Pittet D, Dharan S, Touveneau S, Sauvan V, Perneger TV. Bacterial contamination of the hands of hospital staff during routine patient care. Arch Intern Med 1999;159:821-826.

10. Pittet $D$, Hugonnet $S$, Harbarth $S$, et al. Effectiveness of a hospital-wide programme to improve compliance with hand hygiene. Infection Control Programme. Lancet 2000;356: 1307-1312.

11. Larson EL, Early E, Cloonan P, Sugrue S, Parides M. An organizational climate intervention associated with increased handwashing and decreased nosocomial infections. Behav Med 2000;26:14-22.

12. Boyce JM, Pittet D. Guideline for Hand Hygiene in HealthCare Settings: recommendations of the Healthcare Infection Control Practices Advisory Committee and the HICPAC/ SHEA/APIC/IDSA Hand Hygiene Task Force. Infect Control Hosp Epidemiol 2002;23(Suppl. 12):S3-S40.

13. Klingenberg C, Glad GT, Olsvik R, Flaegstad T. Rapid PCR 
detection of the methicillin resistance gene, mecA, on the hands of medical and non-medical personnel and healthy children and on surfaces in a neonatal intensive care unit. Scand J Infect Dis 2001;33:494-497.

14. Cespedes C, Miller M, Quagliarello B, Vavagiakis P, Klein RS, Lowy FD. Differences between Staphylococcus aureus isolates from medical and nonmedical hospital personnel. J Clin Microbiol 2002;40:2594-2597.

15. Lee YL, Cesario T, Lee R, et al. Colonization by Staphylococcus species resistant to methicillin or quinolone on hands of medical personnel in a skilled-nursing facility. Am J Infect Control 1994;22:346-351.

16. Larson EL. Persistent carriage of Gram-negative bacteria on hands. Am J Infect Control 1981;9:112-119.

17. McBride ME, Montes LF, Fahlberg WJ, Knox JM. Microbial flora of nurses' hands. II. Qualitative differences in occupational groups. Int J Dermatol 1974;13:197-204.

18. McBride ME, Montes LF, Fahlberg WJ, Knox JM. Microbial flora of nurses' hands. I. Quantitative differences in bacterial population between nurses and other occupational groups. Int J Dermatol 1972;11:49-53.

19. Namura S, Nishijima S, Higashida T, Asada Y. Staphylococcus aureus isolated from nostril anteriors and subungual spaces of the hand: comparative study of medical staff, patients, and normal controls. J Dermatol 1995;22:175-180.

20. McBride ME, Montes LF, Fahlberg WJ, Knox JM. Microbial flora of nurses' hands. III. The relationship between staphylococcal skin populations and persistence of carriage. Int J Dermatol 1975;14:129-135.

21. Slight PH, Weber JM, Campos JM, Plotkin SA. Oxacillinresistant coagulase-negative staphylococcal carriage rates in neonatal intensive care nurses and non-patient care hospital personnel. Am J Infect Control 1987;15:29-32.

22. Alghaithy AA, Bilal NE, Gedebou M, Weily AH. Nasal carriage and antibiotic resistance of Staphylococcus aureus isolates from hospital and non-hospital personnel in Abha, Saudi Arabia. Trans R Soc Trop Med Hyg 2000;94:504-507.

23. Guenthner SH, Hendley JO, Wenzel RP. Gram-negative bacilli as nontransient flora on the hands of hospital personnel. J Clin Microbiol 1987;25:488-490.
24. Horn WA, Larson EL, McGinley KJ, Leyden JJ. Microbial flora on the hands of health care personnel: differences in composition and antibacterial resistance. Infect Control Hosp Epidemiol 1988;9:189-193.

25. Cohen ML. Epidemiological factors influencing the emergence of antimicrobial resistance. Ciba Found Symp 1997; 207:223-231 \& 231-227.

26. Levy SB. Antibiotic resistance: consequences of inaction. Clin Infect Dis 2001;33(Suppl. 3):S124-S129.

27. Levy SB. Factors impacting on the problem of antibiotic resistance. J Antimicrob Chemother 2002;49:25-30.

28. Larson E, Lin SX, Gomez-Duarte C. Prevalence and correlates of antibiotic use in 631 hispanic households in New York City. Emerg Infect Dis 2003; in press.

29. Gupta K. Addressing antibiotic resistance. Am J Med 2002; 113(Suppl. 1A):29S-34S.

30. Karlowsky JA, Jones ME, Thornsberry C, Critchley I, Kelly LJ, Sahm DF. Prevalence of antimicrobial resistance among urinary tract pathogens isolated from female outpatients across the US in 1999. Int J Antimicrob Agents 2001;18: 121-127.

31. Gupta K, Hooton TM, Stamm WE. Increasing antimicrobial resistance and the management of uncomplicated community-acquired urinary tract infections. Ann Intern Med 2001; 135:41-50.

32. MMWR. Increases in fluoroquinolone-resistant Neisseria gonorrhoeae-Hawaii and California, 2001. MMWR Morb Mortal Wkly Rep 2002;51:1041-1044.

33. Karlowsky JA, Kelly LJ, Thornsberry C, Jones ME, Sahm DF. Trends in antimicrobial resistance among urinary tract infection isolates of Escherichia coli from female outpatients in the United States. Antimicrob Agents Chemother 2002;46:2540-2545.

34. Sanders JW, Isenbarger DW, Walz SE, et al. An observational clinic-based study of diarrheal illness in deployed United States military personnel in Thailand: presentation and outcome of campylobacter infection. Am J Trop Med Hyg 2002;67:533-538. 